\title{
Score Based Risk Assessment of Lung Cancer and its Evaluation for Bangladeshi People
}

\author{
Roushney Fatima Mukti ${ }^{1}$, Pratul Dipta Samadder ${ }^{1}$, Abdullah Al Emran ${ }^{1 \&}$, \\ Farzana Ahmed $^{2 \& *}$, Iqbal Bin Imran ${ }^{3}$, Anyanna Malaker ${ }^{1}$, Sabina Yeasmin ${ }^{4}$
}

\begin{abstract}
Background: The problem of cancer, especially lung cancer, is very acute in Bangladesh. The present study was conducted to evaluate the risk of lung cancer among Bangladeshi people based on hereditary, socio-economic and demographic factors. Materials and Methods: This study was carried out in 208 people (patients-104, controls-104) from January 2012 to September 2013 using a structured questionnaire containing details of lung cancer risk factors including smoking, secondhand smoke, tobacco leaf intake, age, gender, family history, chronic lung diseases, radiotherapy in the chest area, diet, obesity, physical activity, alcohol consumption, occupation, education, and income. Descriptive statistics and testing of hypotheses were used for the analysis using SPSS software (version 20). Results: According to this study, lung cancer was more prevalent in males than females. Smoking was the highest risk factor $(O R=9.707 ; R R=3.924$; sensitivity $=0.8872$ and $P<0.0001)$ followed by previous lung disease (asthma, tuberculosis etc.) $(\mathrm{OR}=7.095 ; \mathrm{R}=1.508$; sensitivity=0.316 and $\mathrm{P}<0.0001)$ ) for male patients. Highly cooked food $(O R=2.485 ; R R=1.126 ;$ sensitivity=0.418 and $P=0.004))$ and also genetic inheritance $(O R=1.93 ; R R=1.335$; sensitivity=0.163 and $P=0.138)$ demonstrated significant correlation with lung cancer as risk factors after these two and alcohol consumption was not prevalent. On the other hand, for female patients, tobacco leaf intake represented the highest risk $(O R=2.00 ; R R=1.429$; sensitivity $=0.667$ and $P=0.5603)$ while genetic inheritance and highly cooked food also correlate with lung cancer but not so significantly. Socioeconomic status and education level also play important roles in causing lung cancer. Some $\mathbf{7 8 . 5 \%}$ male and $\mathbf{8 3 . 3 \%}$ of female cancer patients were rural residents, while $58.2 \%$ lived at the margin or below the poverty line. Most male $(39.8 \%)$ and female $(\mathbf{5 0 . 0} \%)$ patients had completed only primary level education, and $27.6 \%$ male and $33.3 \%$ female patients were illiterate. Smoking was found to be more prevalent among the less educated persons. Conclusions: The results obtained in this study indicate the importance of creating awareness about lung cancer risk factors among Bangladeshi people and making appropriate access to health services for the illiterate, poor, rural people.
\end{abstract}

Keywords: Lung cancer - risk assessment - smoking - genetic factor - socio-demographics - awareness - Bangladesh

Asian Pac J Cancer Prev, 15 (17), 7021-7027

\section{Introduction}

According to the World Health Organisation, cancer is the leading cause of death worldwide as it accounted for 7.4 million deaths (around 13\% of all deaths) in 2004 and lung cancer is among the five main types of cancer leading to overall cancer mortality contributing about 1.3 million deaths per year globally.

Lung cancer was the most frequent malignant disease and also the most common cause of death from cancer, with 1.38 million deaths ( $18.2 \%$ of the total) by 2008 in the world (Ferlay et al., 2010) and almost half (49.9\%) of the lung cancer cases occur in the developing countries (Siegel et al., 2013). Unfortunately no reliable statistical data about cancer are available for most developing countries and particularly in Bangladesh. In the light of the statistics available from the World Health Organisation, cancer incidence, prevelence and mortality can be estimated approximately as 2,00,000, 8,00,000 and 1,50,000 respectively for the 130 million people of Bangladesh. Based on the World Health Statistics, new cancer cases in Bangladesh have been estimated at 167 per 1,00,000 population. Based on the data available from the Radiotherapy Department of the Dhaka Medical College and Hospital, $21 \%$ male in our country suffer from lung cancer. Illiteracy, inadequate knowledge about health, poverty, chronic infection, and malnutrition are continuously adding additional threat on the huge burden

${ }^{I}$ Department of Biotechnology and Genetic Engineering, Mawlana Bhashani Science and Technology University, ${ }^{2}$ Department of Mathematics and Natural Sciences, BRAC University, Bangladesh, ${ }^{3}$ Faculty of Science and Forestry, University of Eastern Finland, Finland, ${ }^{4}$ Department of Genetic Engineering and Biotechnology, University of Dhaka, Bangladesh ${ }^{\&}$ Equal contributors *For correspondence:farzanageb@gmail.com 
of cancers in Bangladesh. Lung cancer is the leading cancer among males and third most common cancer among females in Bangladesh (Islam et al 2012; Sarker et al., 2012).

According to the International Agency for Research on Cancer (IARC) and Division of Cancer Prevention and Control, National Center for Chronic Disease Prevention and Health Promotion, USA, smoking and secondhand smoke, various exposures at home and work, family history, radiation therapy to the chest can cause lung cancer. Smoking and tobacco use cause $90 \%$ of all lung cancer deaths worldwide (Wingo et al., 1999; Thun et al., 2012). A causal association has been established between exposure to environmental carcinogens and lung cancer and a number of workplace exposures have been classified as causes of lung cancer by IARC (Cogliano et al., 2011) which includes exposure to radon, asbestos, silica dust, TCDD, welding fumes, arsenic etc. It has been estimated that in the UK, around $21 \%$ of lung cancers in men and around $4 \%$ in women are linked to occupational exposures (Rushton et al., 2012). In several Asian populations, an increased risk of lung cancer is present in women from indoor pollution from cooking and heating (Paolo et al., 2003). It is estimated that radiotherapy treatment for a previous cancer is associated with around 320 cases of lung cancer in the UK each year (Parkin and Darby, 2011). Family history of lung cancer in a first-degree relative was associated with a $51 \%$ increased risk of lung cancer, independent of smoking and other relevant factors and the effect is stronger when the affected relative is a sibling (82\% risk increase) rather than a parent (25-37\% risk increase) (Cote et al., 2012). History of pneumonia can be associated with $36 \%$ increased lung cancer risk in never-smokers, and a $43 \%$ increase in ever- and never-smokers combined and people with a previous diagnosis of tuberculosis (TB) have around double the lung cancer risk (Brenner et al., 2011). People with asthma have a higher risk of being diagnosed with lung cancer in the two years following their asthma diagnosis (Rosenberger et al., 2012). There is limited-suggestive evidence that red meat, processed meat, total fat, butter and retinol (vitamin A) supplements (in smokers only), may increase the risk of lung cancer and limited evidence that non-starchy vegetables, selenium in foods (e.g. nuts, cereals and meat) or supplements, and foods containing quercetin may protect against lung cancer and there is probable evidence that fruit (particularly fruit containing carotenoids) protects against lung cancer (WCRF/AICR, 2007). A diet rich in fresh vegetables and cheese seems to be protective (Kreuzer et al., 2002). Higher levels of physical activity are associated with $20-40 \%$ reductions in lung cancer risk and the effect is stronger in smokers than non-smokers (Friedenreich et al., 2010).

Therefore the main objective of the present study was to carry out a statistical investigation for evaluation of the risk factors of lung cancer for Bangladeshi people and to understand the present condition of lung cancer patients in Bangladesh so that it may help to promote public awareness for prevention of lung cancer.

\section{Materials and Methods}

\section{Study design and participants}

The study was designed through extensive literature review from PubMed and from field survey. Because of the exploratory nature of the study, a cross-sectional, self-administered questionnaire-based survey was carried out. Patients' data were collected from the patients, who have histologically proven lung cancer, from the National Cancer Research Institute and Hospital (NICRH), Mohakhali, Dhaka and Dhaka Medical College and Hospital (DMCH), Dhaka and control samples were collected from population of different regions of Bangladesh.

\section{Questionnaire design}

Extensive review of literature, exploratory research and qualitative piloting informed the development and refinement of a structured questionnaire in English. The questionnaire was close and open ended including series of questions about the knowledge of known risk factors associated with lung cancer such as age, smoking status, passive smoking, tobacco leaf intake, hereditary factor, chronic lung disease, radiotherapy, diet, alcohol consumption, obesity, physical activity etc. The gender, educational level, income, living place and occupation were considered in the analysis to mediate the sociodemographic factors which had an influence on other risk factors.

\section{Data collection}

This study was carried out between 01 January 2012 and 31 September 2013. A total of 104 patient's data were collected, comprising 98 males $(94.2 \%)$ and 6 females $(5.8 \%)$ of the total study samples and 104 control groups (98 male and 6 female) were randomly selected from different areas of Bangladesh. Oral consent was taken from all subjects before data collection and the study subjects were requested to complete the provided questionnaires. The authors described the purpose and process of the survey to the people, gave instructions for completing the questionnaire, and emphasized the confidentiality and anonymity of the responses. The questionnaires were completed and collected under the supervision of the authors. Anthropometric data of control group were collected according to standard techniques (De Onis, 1996) and samples' data were collected from their medical report. In this study, body weight $(\mathrm{W})$, height $(\mathrm{H})$ was taken to calculate BMI $\left(\mathrm{W} / \mathrm{H}^{2}\right)$. Age was estimated from birth certificates.

\section{Data analysis}

Collected data from sample and control were edited during and after collection, coded, classified, tabulated, and checked further for any missing information. The total risk factors and socio demographic data were analyzed with correspond to gender to evaluate the risk factors those are crucially responsible for lung cancer among male and female in Bangladesh. The data were analyzed using MS Excel spread sheet 2007, Statistical Package for the Social Sciences (SPSS) Version 20.0. The chi-square 
test was used to examine the association and significance between different variables. A p-value of $<0.05$ was used to establish statistical significance. Odd ratio (at 95\% confidence Interval) more than 2.00 represents the significant correlation with lung cancer and associated risk factor.

\section{Results}

In the 104 samples, the mean age of patient was $56.99 \pm$ SD12.542 years, and mean BMI was 19.035 SD3.3925, where 98(94.2\%) were male and 6(5.8\%) were female. In the control group, we selected 104 individual (male $94.2 \%$ and female 5.8\%) from different areas of Bangladesh. The mean age and BMI of control groups were respectively, age 48.27 \pm SD 10.517 and BMI mean $21.8231 \pm$ SD 2.9359. Total $88.78 \%$ (among male) of the study samples are smokers and rest of the sample groups smoke occasionally or not at all. No smoking patient was found among female patients. Table 1 shows the frequency distribution of study samples and controls. From Table 1, it is clearly seen that, smoking (for male) $(87 \%, \mathrm{P}<0.0001)$ and highly cooked food $(\mathrm{p}=0.222)$ are highly associated with lung cancer for Bangladeshi people. Tobacco leaf intake represents higher risk for female than male.

Table 2 represents the risk factors and their association with lung cancer for Bangladeshi people in corresponding with Odd ratio, Relative Risk, Sensitivity and P-value. This table reveals significant difference in smoking and alcohol prevalence amongst males and females. In our study sample $88.78 \%$ male patients are smoker and smoking belongs to highest risk factor $(\mathrm{OR}=9.707$; $\mathrm{RR}=3.924$; Sensitivity $=0.8872$ and $\mathrm{P}<0.0001$ ) according to our statistical analysis. Then previous lung diseases (asthma, tuberculosis etc.) shows the second risk factor $(\mathrm{OR}=7.095$;
$\mathrm{RR}=1.508$; Sensitivity $=0.316$ and $\mathrm{P}<0.0001)$ ) for male patients. Highly cooked food $(\mathrm{OR}=2.485$; $\mathrm{RR}=1.126$; Sensitivity $=0.418$ and $\mathrm{P}=0.004)$ ) and also Genetic inheritance $(\mathrm{OR}=1.93 ; \mathrm{RR}=1.335$; Sensitivity $=0.163$ and $\mathrm{P}=0.138$ ) depict significant correlation with lung cancer as risk factors after smoking and previous lung diseases. Alcohol consumption is not so prevalent for Bangladeshi people. On the other hand, tobacco leaf intake represent the highest risk $(\mathrm{OR}=2.00 ; \mathrm{RR}=1.429 ;$ Sensitivity $=0.667$ and $\mathrm{P}=0.5603$ ) for female patients. Genetic inheritance and highly cooked food also correlate with lung cancer of female patients but not so significant. In Bangladesh, lung cancer is more prevalence for male than female. Score based risk factor assessment of lung cancer for Bangladeshi people are shown in Figure 1.

According to statistical data analysis (based on Odd ratio and Relative Risk) we are able to find out risk factors and their scoring within male and female patients of lung cancer in Bangladesh. Figure 1 shows the rate of risk with based on scoring of relative risk. Score based arrangement of lung cancer risk factors for male: Smoking $>$ Previous lung disease $>$ Highly cooked food $>$ Genetic inheritance $>$

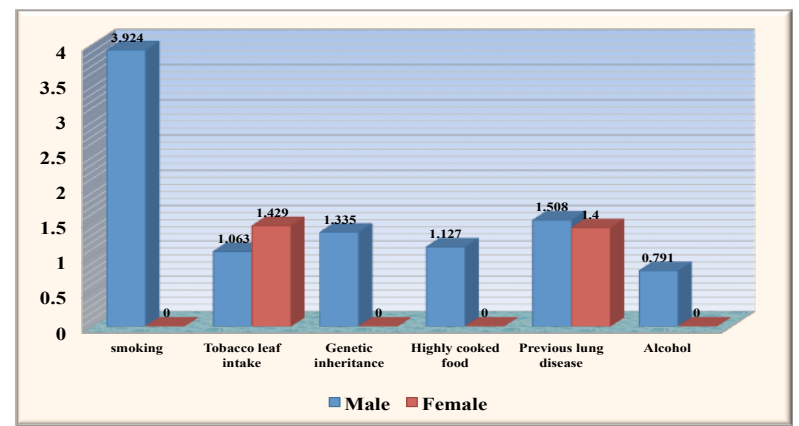

Figure 1. Assessment of Score Based Risk Factors of Lung Cancer for Bangladeshi People

Table 1. Frequency Distribution and Significant Variation of Risk Factors among Cancer Patients and Control Groups (*Statistically Significant)

\begin{tabular}{|c|c|c|c|c|c|c|c|c|c|}
\hline \multirow[t]{3}{*}{ Risk Factors } & \multicolumn{4}{|c|}{ Patients $(\mathrm{N}=104)$} & \multicolumn{4}{|c|}{ Controls $(\mathrm{N}=104)$} & \multirow[t]{3}{*}{$\mathrm{P}$ value } \\
\hline & \multicolumn{2}{|c|}{ Male $n=98,(94.2 \%)$} & \multicolumn{2}{|c|}{ Female $n=6,(5.8 \%)$} & \multicolumn{2}{|c|}{ Male $n=98,(94.2 \%)$} & \multicolumn{2}{|c|}{ Female $n=6,(5.8 \%)$} & \\
\hline & Yes & No & Yes & $\mathrm{No}$ & Yes & No & Yes & No & \\
\hline Smoking & $87(88.78 \%)$ & $11(11.22 \%)$ & 0 & $6(100 \%)$ & $44(44.89 \%)$ & $54(55.11 \%)$ & 0 & $6(100 \%)$ & $<0.0001^{*}$ \\
\hline Tobacco leaf intake & $47(48.0 \%)$ & $51(52.0 \%)$ & $4(66.7 \%)$ & $2(33.33 \%)$ & $44(44.9 \%)$ & $54(55.1 \%)$ & $3(50.0 \%)$ & $3(50.0 \%)$ & 0.375 \\
\hline Genetic inheritance & $16(16.32 \%)$ & $82(83.7 \%)$ & 0 & $6(100 \%)$ & $9(9.2 \%)$ & $89(90.8 \%)$ & $1(6.7 \%)$ & $5(83.3 \%)$ & 0.561 \\
\hline Highly Cooked food & $\begin{array}{l}41(41.8 \%) \\
\text { Daily }\end{array}$ & $\begin{array}{l}57(58.2 \%) \\
\text { Not daily }\end{array}$ & $1(16.7 \%)$ & $5(83.3 \%)$ & $22(22.4 \%)$ & $76(77.6 \%)$ & 0 & $6(100 \%)$ & $0.222 *$ \\
\hline $\begin{array}{l}\text { Previous lung disease } \\
\text { (Asthma,TB) }\end{array}$ & $31(31.6 \%)$ & $67(68.4 \%)$ & $3(50 \%)$ & $3(50 \%)$ & $6 \quad(6.1 \%)$ & $92(93.9 \%)$ & $2(33.3 \%)$ & $4(66.7 \%)$ & 0.352 \\
\hline Alcohol & $\begin{array}{l}4(4.1 \%) \\
\text { Daily }\end{array}$ & $94(95.9 \%)$ & 0 & $6(100 \%)$ & $\begin{array}{l}6(6.1 \%) \\
\text { Daily }\end{array}$ & $92(93.9 \%)$ & 0 & $6(00 \%)$ & 0.881 \\
\hline
\end{tabular}

Table 2. Assessment of Risk Factors of Lung Cancer with Odd ratio, Relative Risk and p value (At 95\% CI, NaN=Not a number, *Statistically Significant)

\begin{tabular}{|c|c|c|c|c|c|c|c|c|}
\hline \multirow[t]{2}{*}{ Risk Factors } & \multicolumn{2}{|c|}{ Odd Ratio } & \multicolumn{2}{|c|}{ Relative Risk } & \multicolumn{2}{|c|}{ Sensitivity } & \multicolumn{2}{|c|}{$\mathrm{p}$ value } \\
\hline & Male & Female & Male & Female & Male & Female & Male & Female \\
\hline$\overline{\text { Smoking }}$ & 9.707 & $\mathrm{NaN}$ & 3.924 & $\mathrm{NaN}$ & 0.8872 & 0 & $<0.0001 *$ & 1 \\
\hline Tobacco Leaf intake & 1.13 & 2 & 1.063 & 1.429 & 0.48 & 0.667 & 0.667 & 0.5603 \\
\hline Genetic inheritance & 1.93 & 0 & 1.335 & 0 & 0.163 & 0 & 0.138 & 1 \\
\hline Cooked food Highly & 2.485 & $\mathrm{NaN}$ & 1.127 & $\mathrm{NaN}$ & 0.418 & 0 & $0.004 *$ & 1 \\
\hline Previous lung disease (Asthma,Tb) & 7.095 & 2 & 1.508 & 1.4 & 0.316 & 0.5 & $<0.0001 *$ & 0.558 \\
\hline Alcohol & 0.652 & $\mathrm{NaN}$ & 0.791 & $\mathrm{NaN}$ & 0.041 & 0 & 0.518 & 1 \\
\hline
\end{tabular}


Tobacco leaf intake $>$ Alcohol consumption and for female: Tobacco leaf intake $>$ Previous lung disease $>$ Highly cooked food $>$ Genetic inheritance.

The sensitivity and specificity of risk factors were analyzed through Receiver Operating Characteristic (ROC) curves (Figure 2). Each point on the ROC curve represents a sensitivity/specificity pair corresponding to our particular decision threshold value. The area under the ROC curve (AUC) is a measureable parameter that can distinguish between two diagnostic groups (diseased/ normal).This ROC curve depicts graph of sensitivity (y-axis) vs 1-specificity (x-axis). Maximizing sensitivity corresponds to some large y value on the ROC curve and maximizing specificity corresponds to a small $\mathrm{x}$ value on the ROC curve. As our study samples consist $94.2 \%$ male patients and larger values of the test result variable(s) indicate stronger evidence for a positive actual state so our positive actual is male. Due to the low number female samples statistical analysis become slightly biased. The smallest cutoff value is the minimum observed test $(-1)$, and the largest cutoff value is the maximum observed test value $(+1)$. All the other cutoff values are the averages of two consecutive ordered observed test values. The test result variable(s): smoking, tobacco leaf intake, previous lung disease history; family member diagnosed with lung cancer has at least one tie between the positive actual state group and the negative actual state group. Area under the Curve (AUC) smoking (0.515); tobacco leaf intake $(0.427)$; previous lung disease $(0.595)$; genetic inheritance (0.4).

In further, the socio-demographic conditions of lung cancer were correlated with respect to annual income, residential area, occupation and their educational level.
Most of the study samples (cancer patients) are from the rural area, $78.5 \%$ male and $83.3 \%$ female patients live in rural area and their work places are also in rural area. Maximum male lung cancer patients' occupations (45.9\%) are related mostly with business and then with agriculture, in fact most of them are farmers $(26.5 \%)$. On the other hand, most of the female patients $(83.3 \%)$ are housewives. According to our study, 58.2\% lung cancer patients are not solvent; most of them live in the margin or bellow the poverty line. So they are unable to afford for the early diagnosis of lung cancer and it's a matter of great regret that most of our study patients are in metastasis stage.

Table 5 describes the socio economic character of lung cancer patients in Bangladesh. In this study, we have found $32.7 \%$ patients belong to annual income of 100000 to 150000 tk range (USD 1288to 1932) and 25\% people belong to annual income of USD 644-1288 range.

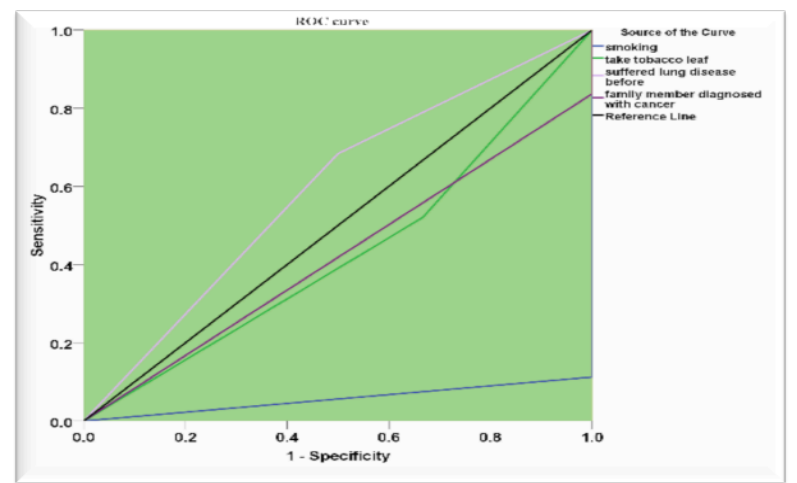

Figure 2. Complete Sensitivity and Specificity Report of Risk Factors of Lung Cancer by ROC Curve Analysis

Table 3. Correlation among Gender, residential Area and Work Place of Cancer Patients (Pearson Chi-square value 26.952 and df 1 , *Statistically Significant)

\begin{tabular}{|c|c|c|c|c|c|c|c|}
\hline \multirow[t]{2}{*}{ Gender } & & & & \multicolumn{2}{|c|}{ Residential Area } & \multirow[t]{2}{*}{ Total } & \multirow[t]{2}{*}{ P-value } \\
\hline & & & & Rural & Urban & & \\
\hline \multirow[t]{12}{*}{ Male } & \multirow[t]{8}{*}{ Work Place } & \multirow[t]{4}{*}{ Rural } & Count & 62 & 3 & 65 & \\
\hline & & & $\%$ within workplace & $96.90 \%$ & $3.10 \%$ & $100.00 \%$ & \\
\hline & & & $\%$ within residential area & $78.50 \%$ & $11.10 \%$ & $66.00 \%$ & \\
\hline & & & $\%$ of Total & $63.90 \%$ & $2.10 \%$ & $66.00 \%$ & \\
\hline & & \multirow[t]{4}{*}{ Urban } & Count & 17 & 16 & 33 & \\
\hline & & & $\%$ within workplace & $51.50 \%$ & $48.50 \%$ & $100.00 \%$ & \\
\hline & & & $\%$ within residential area & $21.50 \%$ & $88.90 \%$ & $34.00 \%$ & \\
\hline & & & $\%$ of Total & $17.50 \%$ & $16.50 \%$ & $34.00 \%$ & \\
\hline & \multirow[t]{4}{*}{ Total } & & Count & 79 & 18 & 98 & \\
\hline & & & $\%$ within workplace & $81.40 \%$ & $18.60 \%$ & $100.00 \%$ & \\
\hline & & & $\%$ within residential area & $100.00 \%$ & $100.00 \%$ & $100.00 \%$ & $<0.0001 *$ \\
\hline & & & $\%$ of Total & $81.40 \%$ & $18.60 \%$ & $100.00 \%$ & \\
\hline \multirow[t]{12}{*}{ Female } & \multirow[t]{8}{*}{ Workplace } & \multirow[t]{4}{*}{ Rural } & Count & 5 & & 5 & \\
\hline & & & $\%$ within workplace & $100.00 \%$ & & $100.00 \%$ & \\
\hline & & & $\%$ within residential area & $83.30 \%$ & & $83.30 \%$ & \\
\hline & & & $\%$ of Total & $83.30 \%$ & & $83.30 \%$ & \\
\hline & & \multirow[t]{4}{*}{ Urban } & Count & 1 & & 1 & \\
\hline & & & $\%$ within workplace & $100.00 \%$ & & $100.00 \%$ & \\
\hline & & & $\%$ within residential area & $16.70 \%$ & & $16.70 \%$ & \\
\hline & & & $\%$ of Total & $16.70 \%$ & & $16.70 \%$ & \\
\hline & \multirow[t]{4}{*}{ Total } & & Count & 6 & & 6 & \\
\hline & & & $\%$ within workplace & $100.00 \%$ & & $100.00 \%$ & $<0.0001^{*}$ \\
\hline & & & $\%$ within residential area & $100.00 \%$ & & $100.00 \%$ & \\
\hline & & & $\%$ of Total & $100.00 \%$ & & $100.00 \%$ & \\
\hline
\end{tabular}


Score Based Risk Assessment of Lung Cancer and its Evaluation for Bangladeshi People

Table 4. Correlation among Gender and Occupation of the Lung Cancer Patients (*statistically significant)

\begin{tabular}{|c|c|c|c|c|c|c|c|c|c|c|}
\hline \multirow[t]{2}{*}{ Gender } & & \multicolumn{7}{|c|}{ Occupation } & \multirow[t]{2}{*}{ Total } & \multirow[t]{2}{*}{ P-value } \\
\hline & & Farmer & Business & Labor & Teacher & Job & housewife & student & & \\
\hline \multirow[t]{4}{*}{ Male } & Count & 26 & 45 & 11 & 3 & 11 & 0 & 2 & 98 & \\
\hline & $\%$ within gender & $26.50 \%$ & $45.90 \%$ & $11.20 \%$ & $3.10 \%$ & $11.20 \%$ & $0.00 \%$ & $2.00 \%$ & $100.00 \%$ & \\
\hline & $\%$ within Occupation & $100.00 \%$ & $100.00 \%$ & $100.00 \%$ & $100.00 \%$ & $100.00 \%$ & $0.00 \%$ & $66.70 \%$ & $94.20 \%$ & \\
\hline & $\%$ of Total & $25.00 \%$ & $43.30 \%$ & $10.60 \%$ & $2.90 \%$ & $10.60 \%$ & $0.00 \%$ & $1.90 \%$ & $94.20 \%$ & \\
\hline \multirow[t]{4}{*}{ Female } & Count & 0 & 0 & 0 & 0 & 0 & 5 & 1 & 6 & \\
\hline & $\%$ within gender & $0.00 \%$ & $0.00 \%$ & $0.00 \%$ & $0.00 \%$ & $0.00 \%$ & $83.30 \%$ & $16.70 \%$ & $100.00 \%$ & $<0.0001^{*}$ \\
\hline & $\%$ within Occupation & $0.00 \%$ & $0.00 \%$ & $0.00 \%$ & $0.00 \%$ & $0.00 \%$ & $100.00 \%$ & $33.30 \%$ & $5.80 \%$ & \\
\hline & $\%$ of Total & $0.00 \%$ & $0.00 \%$ & $0.00 \%$ & $0.00 \%$ & $0.00 \%$ & $4.80 \%$ & $1.00 \%$ & $5.80 \%$ & \\
\hline \multirow[t]{4}{*}{ Total } & Count & 26 & 45 & 11 & 3 & 11 & 5 & 3 & 104 & \\
\hline & $\%$ within gender & $25.00 \%$ & $43.30 \%$ & $10.60 \%$ & $2.90 \%$ & $10.60 \%$ & $4.80 \%$ & $2.90 \%$ & $100.00 \%$ & \\
\hline & $\%$ within Occupation & $100.00 \%$ & $100.00 \%$ & $100.00 \%$ & $100.00 \%$ & $100.00 \%$ & $100.00 \%$ & $100.00 \%$ & $100.00 \%$ & \\
\hline & $\%$ of Total & $25.00 \%$ & $43.30 \%$ & $10.60 \%$ & $2.90 \%$ & $10.60 \%$ & $4.80 \%$ & $2.90 \%$ & $100.00 \%$ & \\
\hline
\end{tabular}

Table 5. Cross Tabulation of Gender and Annual Income of Cancer Patients (Pearson Chi-square value 55.220 and df 6 , *statistically significant)

\begin{tabular}{|c|c|c|c|c|c|c|c|c|c|}
\hline \multirow[t]{2}{*}{ Gender } & & \multirow[b]{2}{*}{ No income } & \multirow[b]{2}{*}{$\begin{array}{c}50000- \\
100000 \mathrm{tk}\end{array}$} & \multicolumn{5}{|c|}{ Annual income } & \multirow[t]{2}{*}{ P-value } \\
\hline & & & & $\begin{array}{c}100000- \\
150000 \mathrm{tk}\end{array}$ & $\begin{array}{c}150000- \\
200000 \text { tk }\end{array}$ & $\begin{array}{c}200000- \\
250000 \text { tk }\end{array}$ & $\begin{array}{c}250000- \\
300000 \text { tk }\end{array}$ & $>300000 \mathrm{tk}$ & \\
\hline \multirow[t]{4}{*}{ Male } & Count & 1 & 25 & 32 & 16 & 13 & 5 & 6 & 98 \\
\hline & $\%$ within gender & $1.00 \%$ & $25.50 \%$ & $32.70 \%$ & $16.30 \%$ & $13.30 \%$ & $5.10 \%$ & $6.10 \%$ & $100.00 \%$ \\
\hline & $\%$ within annual income & $20.00 \%$ & $92.60 \%$ & $100.00 \%$ & $100.00 \%$ & $100.00 \%$ & $100.00 \%$ & $100.00 \%$ & $94.20 \%$ \\
\hline & $\%$ of Total & $1.00 \%$ & $24.00 \%$ & $30.80 \%$ & $15.40 \%$ & $12.50 \%$ & $4.80 \%$ & $5.80 \%$ & $94.20 \%$ \\
\hline \multirow[t]{4}{*}{ Female } & Count & 4 & 2 & 0 & 0 & 0 & 0 & 0 & 6 \\
\hline & $\%$ within gender & $66.70 \%$ & $33.30 \%$ & $0.00 \%$ & $0.00 \%$ & $0.00 \%$ & $0.00 \%$ & $0.00 \%$ & $100.00 \%$ \\
\hline & $\%$ within annual income & $80.00 \%$ & $7.40 \%$ & $0.00 \%$ & $0.00 \%$ & $0.00 \%$ & $0.00 \%$ & $0.00 \%$ & $5.80 \%$ \\
\hline & $\%$ of Total & $3.80 \%$ & $1.90 \%$ & $0.00 \%$ & $0.00 \%$ & $0.00 \%$ & $0.00 \%$ & $0.00 \%$ & $5.80 \%$ \\
\hline \multirow[t]{4}{*}{ Total } & Count & 5 & 27 & 32 & 16 & 13 & 5 & 6 & $<0.0001 *$ \\
\hline & $\%$ within gender & $4.80 \%$ & $26.00 \%$ & $30.80 \%$ & $15.40 \%$ & $12.50 \%$ & $4.80 \%$ & $5.80 \%$ & $100.00 \%$ \\
\hline & $\%$ within annual income & $100.00 \%$ & $100.00 \%$ & $100.00 \%$ & $100.00 \%$ & $100.00 \%$ & $100.00 \%$ & $100.00 \%$ & $100.00 \%$ \\
\hline & $\%$ of Total & $4.80 \%$ & $26.00 \%$ & $30.80 \%$ & $15.40 \%$ & $12.50 \%$ & $4.80 \%$ & $5.80 \%$ & $100.00 \%$ \\
\hline
\end{tabular}

Table 6. Cross Tabulation within Gender and Education of Cancer Patients (Pearson Chi-square value 0.793 and df 3 , at $95 \% \mathrm{CI}$ )

\begin{tabular}{|c|c|c|c|c|c|c|c|c|}
\hline \multirow[t]{2}{*}{ Gender } & & & \multicolumn{4}{|c|}{ Education } & \multirow[t]{2}{*}{ Total } & \multirow[t]{2}{*}{ P-value } \\
\hline & & & Primary & Secondary & Higher educated & Illiterate & & \\
\hline & \multirow[t]{4}{*}{ Male } & Count & 39 & 26 & 6 & 27 & 98 & \\
\hline & & $\%$ within gender & $39.80 \%$ & $26.50 \%$ & $6.10 \%$ & $27.60 \%$ & $100.00 \%$ & \\
\hline & & $\%$ within education & $92.90 \%$ & $96.30 \%$ & $100.00 \%$ & $93.10 \%$ & $94.20 \%$ & \\
\hline & & $\%$ of Total & $37.50 \%$ & $25.00 \%$ & $5.80 \%$ & $26.00 \%$ & $94.20 \%$ & \\
\hline & \multirow[t]{8}{*}{ Female } & Count & 3 & 1 & 0 & 2 & 6 & 0.851 \\
\hline & & $\%$ within gender & $50.00 \%$ & $16.70 \%$ & $0.00 \%$ & $33.30 \%$ & $100.00 \%$ & \\
\hline & & $\%$ within education & $7.10 \%$ & $3.70 \%$ & $0.00 \%$ & $6.90 \%$ & $5.80 \%$ & \\
\hline & & $\%$ of Total & $2.90 \%$ & $1.00 \%$ & $0.00 \%$ & $1.90 \%$ & $5.80 \%$ & \\
\hline \multirow[t]{4}{*}{ Total } & & Count & 42 & 27 & 6 & 29 & 104 & \\
\hline & & $\%$ within gender & $40.40 \%$ & $26.00 \%$ & $5.80 \%$ & $27.90 \%$ & $100.00 \%$ & \\
\hline & & $\%$ within education & $100.00 \%$ & $100.00 \%$ & $100.00 \%$ & $100.00 \%$ & $100.00 \%$ & \\
\hline & & $\%$ of Total & $40.40 \%$ & $26.00 \%$ & $5.80 \%$ & $27.90 \%$ & $100.00 \%$ & \\
\hline
\end{tabular}

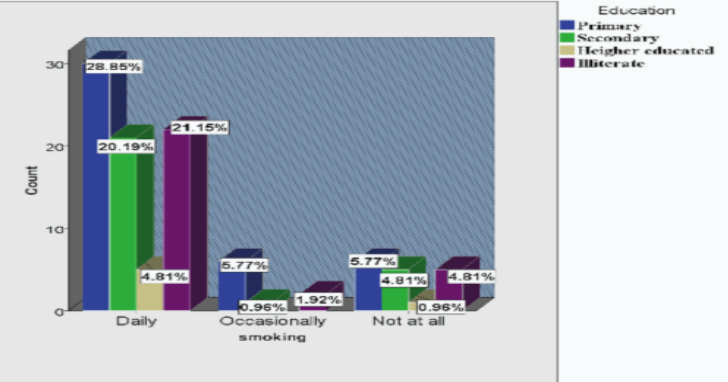

Figure 3. Correlation between Smoking Status and Educational Level of Lung Cancer Patients
So maximum percentage of lung cancer patients are poor and only $6 \%$ patients are rich (annual income more than 5795 USD) according to our study.

Table 6 indicates the educational status of cancer patients. Most of the male (39.8\%) and female (50.0\%) patients have completed only primary level education. Then $27.6 \%$ male and $33.3 \%$ female patients are illiterate and only $6.1 \%$ patients are higher educated. Significant relationship was also found between smoking and educational level of lung cancer patients in Bangladesh. Smoking was found to be more prevalent among the less 
Roushney Fatima Mukti et al

educated person. This relationship is shown in bar diagram (Figure 3). It was found that $28.85 \%$ daily smoker patients have completed primary level education and $21.5 \%$ daily smoker patients are illiterate. Only $4.81 \%$ higher educated patients are daily smoker (Figure 3).

\section{Discussion}

This study shows that lung cancer is more prevelant in male than female and this finding is similar to that were found in previous surveys conducted in Bangladesh. Literature revealed lung cancer as the leading cancer in male in our country (Talukder et al., 2008). In this study, we found out some risk factors and socio-economic, demographic conditions those are highly correlated with lung cancer for Bangladeshi people. We found risk factors those are comparatively higher in correlation with or responsible for lung cancer, are smoking, tobacco leaf intake, previous lung disease (asthma, tuberculosis etc.), genetic inheritance, highly cooked food consumption. It was found that the highest number of cancer patients were among 50-65 year age group which supports the hypothesis of risk of developing lung cancer increases with age (Moore et al., 2010).

Tobacco use, especially cigarette smoking, has been considered as the highest risk factor for lung cancer in different studies worldwide and our study also tells that smoking belongs to the highest risk factor for male and tobacco leaf intake for female for lung cancer incidents in Bangladeshi people, as in other countries of Asia (Ahmed et al., 2013; Kamsa-Ard et al., 2013; Luqman et al., 2014). Though no female patient was found as smoker in our study but females are prone to expose second hand smoke and indoor air pollution. Previous lung disease and genetic inheritance are associated with lung cancer both for male and female and these two factors have been considered as greater risk for lung cancer by IARC. Alcohol consumption has not been found so prevalent for lung cancer in Bangladeshi people, which supports the findings of some meta-analyses that have shown that alcohol intake is not associated with lung cancer risk in never-smokers or ever-smokers (Bagnardi et al., 2011; Chao, 2011).

In our study, smoking was found to be more prevalent in low educational level population, which is similar to the findings supported by other international comparison studies where smoking was found to be more prevalent among the less educated (Chawla et al., 2010; Aarts et al., 2013). Socio-econic factors are also important in Nepal (Hashibe et al., 2011). As cessation of smoking has been associated with a declining risk for lung cancer (Yano et al., 2011), therefore proper counselling, programs and policies to promote cessation and reduce smoking are to be provided by the public health workers and by the government.

World Cancer Research Fund/American Institute for Cancer Research tells that there is limited-suggestive evidence that red meat, processed meat, total fat etc. may increase the risk of lung cancer, but our study found a significant correlation between highly cooked food, for example, highly fried meat, grilled food, open flame cooked meat or fish, junk foods etc and lung cancer risk ).

We found most of our lung cancer patients illiterate and poor rural people who are not conscious about their health due to lack of knowledge and can not afford for the proper treatment after being diseased or diagnosed, so they have a greater risk of suffering from lung cancer death than that of educated and rich people. These findings emphasize the need to develop health education programs that enhance lung cancer knowledge among men and women who are in low socioeconomic groups. So, the government and NGOs should gear up for a population based counselling program.

In conclusion, according to cancer registry report of NICRH, the number of lung cancer patients in Bangladesh is increasing year by year, so it became very urgent to find out the lung cancer risk factors, that is why we conducted this study. The results obtained in this study indicate the importance of creating awareness about lung cancer risk factors among Bangladeshi people as the prevention of lung cancer warrants serious attention. Smoking is the single most preventable risk factor for lung cancer in our country. As we found most of the study patients in metastasis phase, we suggest that attempts should be made to diagnose patients at an early stage, which can come with awareness and use of various diagnostic modalities. Educational qualification and socio-economic and demographic characteristics are significantly related to lung cancer and we may define them as passive risk factors. So steps should be taken to make smooth access to health services and proper knowledge about lung cancer for the illiterate, poor, rural people. This research will be helpful to create a national database of lung cancer based on hereditary, socio-economic and demographic factors as well as can suggest guidelines for other cancers in Bangladesh. This will also suggest the risk of developing lung cancer in control population based on the score of the risk factors which will be certainly helpful for self assessment of individuals and changes their lifestyle to prevent this type of cancer.

\section{References}

Aarts MJ, Kamphuis CB, Louwman MJ et al(2013) Educational inequalities in cancer survival: a role for comorbidities and health behaviours? J Epidemiol Community Health, 67, 365-73

Ahmed K, Emran AA, Jesmin T, et al (2013). Early detection of lung cancer risk using data mining. Asian Pac J Cancer Prev, 14, 595-8.

Bagnardi V, Rota M, Botteri E, et al (2011). Alcohol consumption and lung cancer risk in never smokers: a meta-analysis. Ann Oncol, 22, 2631-39.

Brenner DR, McLaughlin JR, Hung RJ (2011). Previous lung diseases and lung cancer risk: a systematic review and metaanalysis. PLOS ONE, 6, 174-79.

Chao C, Li Q, Zhang F, White E (2011). Alcohol consumption and risk of lung cancer in the VITamins And Lifestyle Study. Nutr Cancer, 63, 880-8.

Chawla R, Sathian B, Mehra A, et al (2010). Awareness and assessment of risk factors for lung cancer in residents of Pokhara valley. Asian Pac J Cancer Prev, 11, 1789-93.

Cogliano VJ, Baan R, Straif K, et al (2011). Preventable exposures associated with human cancers. $J$ Natl Cancer 
$I, \mathbf{1 0 3}, 1827-39$.

Coté ML, Liu M, Bonassi S, Neri M, et al (2012). Increased risk of lung cancer in individuals with a family history of the disease: A pooled analysis from the International Lung Cancer Consortium. Eur J Cancer, 48, 1957-68.

De Onis M, Habicht JP (1996) Anthropometric reference data for international use: recommendations from a world health organization expert committee. Am J Clin Nutrition, 64, 650-8

Ferlay J, Shin HR, Bray F, et al (2010). Cancer incidence and mortality worldwide. GLOBOCAN 2008: IARC cancer Base No.10 [Internet]. Lyon, France: International agency for research on cancer.

Fokhru IM, Nazmul H, Anjuman B, et al ( 2012).Distribution of cancer patients and patterns of cancer treatment at dhaka medical college hospital, Bangladesh. Int Res J Pharmacy, $3,1-5$

Friedenreich CM, Neilson HK, Lynch BM (2010). State of the epidemiological evidence on physical activity and cancer prevention. Eur J Cancer, 46, 2593-604.

Fucic A, Gamulin M, Ferencic Z, et al (2010). Lung cancer and environmental chemical exposure: a review of our current state of knowledge with reference to the role of hormones and hormone receptors as an increased risk factor for developing lung cancer in man. Toxicol Pathol, 38, 849-55.

Hashibe M, Siwakoti B, Wei M, et al (2011). Socioeconomic status and lung cancer risk in Nepal. Asian Pac J Cancer Prev, 12, 1083-8.

Kamsa-Ard S, Promthet S, Lewington S, et al (2013). Association between smoking and mortality: Khon Kaen cohort study, Thailand. Asian Pac J Cancer Prev, 14, 2643-7.

Kreuzer M, Heinrich J, Kreienbrock L, et al (2002). Risk factors for lung cancer among nonsmoking women. Int J Cancer, 100, 706-13

Mohammad Abul Bashar Sarker, Md. Harun-Or-Rashid,Tomoya Hirosawa et al (2012). Trends and distributions of common types of cancer in Bangladesh: results from the cancer registry data of 2008-10, Ann Cancer Res Therapy, 20, 32-38.

Luqman M, Javed MM, Daud S, et al (2014). Risk factors for lung cancer in the Pakistani population. Asian Pac J Cancer Prev, 15, 3035-9.

Moore MA, Ariyaratne Y, Badar F, et al (2010). Cancer epidemiology in South Asia - past, present and future. Asian Pac J Cancer Prev, 11, 49-66.

Parkin DM, Darby SC (2011). Cancers in 2010 attributable to ionising radiation exposure in the UK. Br J Cancer, 105, 57-65.

Rosenberger A, Bickeboller H, McCormack V, et al (2012). Asthma and lung cancer risk: a systematic investigation by the international lung cancer consortium. Carcinogenesis, 33, 587-97.

Rushton L, Hutchings SJ, Fortunato L, et al (2012). Occupational cancer burden in great britain. Br J Cancer, 107, 3-7.

Siegel R, Naishadham D, Jemal A (2013). Cancer statistics, 2013. CA Cancer J Clin, 63, 11-30.

Talukder MH, Jabeen S, Islam MJ, Hussain SMA (2008). Distribution of cancer patients at national institute of cancer research and hospital in 2006. Bangladesh Med J, 37, 2-5.

Thun M, Peto R, Boreham J, Lopez AD(2012). Stages of the cigarette epidemic on entering its second century. Tob Control, 21, 96-101.

Wingo PA, Ries LAG, GiovinoGA, et al (1999). Annual report to the nation on the status of the cancer, 1973-1996, with special section on lung cancer and tobacco smoking. J Natl Cancer Inst, 91, 675-90.

World Cancer Research Fund/American institute for cancer research (WCRF/AICR). food, nutrition, physical activity, and the prevention of cancer: a global perspective. washington DC: AICR, 2007.

Yano T, Haro A, Shikada Y et al (2011).Non-small cell lung cancer in never smokers as a representative 'non-smokingassociated lung cancer': epidemiology and clinical features. Int J Clin Oncol, 16, 287-93. 